\title{
Nanostructural changes in commodity polyethylene during environmental exposure
}

\section{Christopher J. Garvey ${ }^{1,2,3}$, Ron Demjaha ${ }^{2}$, Michael P. Weir ${ }^{4}$, Peter J. Halley ${ }^{5}$, Bronwyn Laycock ${ }^{5}$, Yu-Chieh Hsu ${ }^{5}$, Marianne Impéror-Clerc ${ }^{1}$ and Stéphan Rouzière ${ }^{1}$}

\author{
${ }^{1}$ Laboratoire de Physique des Solides, UMR 8502, CNRS, Université Paris Saclay, 91400 Orsay, France, \\ ${ }^{2}$ Lund Institute for Advanced Neutron and X-ray Science, 22370 Lund, Sweden, \\ ${ }^{3}$ Heinz Maier-Leibnitz Zentrum (MLZ), Lichtenbergstrasse 1 85747, Garching, Germany \\ ${ }^{4}$ School of Physics and Astronomy, University of Nottingham, University Park, Nottingham, NG7 2RD, United Kingdom, \\ ${ }^{5}$ School of Chemical Engineering, The University of Queensland, St Lucia, Qld. 4067, Australia.
}

\author{
christopher.garvey@tum.de
}

Incomplete recrystallization after the melt processing of thermoplastics leads to a kinetically frustrated state in plastic packaging. Release of this frustration by random chain scission during environmental exposure and the associated structural relaxation is a mechanism in the embrittlement and fragmentation for these materials. ${ }^{[1]}$ This mechanism is therefore a major route of physical degradation for the majority of plastic waste. The loss of mechanical properties and barrier properties of the material may catalyse further oxidation of microplastic waste and ultimately limit the lifetime of waste in the environment. After establishing the important role of nanostructure in embrittlement and further degradation we discuss the characterization of this process by X-ray scattering, both in the wide (WAXS) and small angle (SAXS) domains using semi-crystalline polyethylene as a model. These two experimental techniques characterize the packing of polymer chains into crystallites and the arrangement of these crystallites into lamellae respectively. These non-destructive bulk characterization techniques with a minimum of sample preparation offers a rapid and convenient access to relevant nanostructural parameters in order to define the temporal relationship between environmental exposure and structural relaxation. ${ }^{[2,3]}$ Thus the perspective of X-ray scattering provides important insight into the lifetime of thermoplastics in the environment and will allow the engineering of more sustainable materials with optimized and controlled degradation, and thus impact on the environment.

[1] Garvey, C. J., Impéror-Clerc, M., Rouzière, S., Gouadec, G., Boyron, O., Rowenczyk, L., Mingotaud, A. F. \& ter Halle, A. (2020). Environmental Science \& Technology 54, 11173-11181.

[2] Hsu, Y. C., Truss, R. W., Laycock, B., Weir, M. P., Nicholson, T. M., Garvey, C. J. \& Halley, P. J. (2017). Polymer 119, 66-75.

[3] Hsu, Y. C., Weir, M. P., Truss, R. W., Garvey, C. J., Nicholson, T. M. \& Halley, P. J. (2012). Polymer 53, $2385-2393$.

\section{Keywords: commodity plastics; plastic packaging; wide angle X-ray scattering; small angle X-ray scattering}

C.J.G. acknowledges the CNRS and Université Paris-Sud for financial support during his sabbaticals. We would like to thank the Cooperative Research Centre for Polymers for funding parts of this study under project 2.4, Polyolefin-Biopolymer Films for More Sustainable Agricultural Production. 